\title{
PELATIHAN PEMBELAJARAN INOVATIF BERBASIS KARAKTER BERDASARKAN KURIKULUM 2013 BAGI GURU- GURU BAHASA INGGRIS SMP, SMA, DAN SMK SE KABUPATEN MANGGARAI BARAT
}

\author{
Luh Putu Artini 1*, Ni Nyoman Padmadewi² \\ 1 Pendidikan Bahasa Inggris, Program Pascasarjana Universitas Pendidikan Ganesha \\ 2 Pendidikan Bahasa Inggris , Program Pascasarjana Universitas Pendidikan Ganesha
}

\begin{abstract}
Abstrak
Kegiatan Pengabdian pada masyarakat ini memiliki tujuan agar guruguru bahasa Inggris SMP, SMA dan SMK se Kabupaten Manggarai Barat agar memiliki: 1. pengetahuan konsep pembelajaran inovatif sesuai dengan Kurikulum 2013 yang menyasar pencapaian kognitif dan pendidikan

Keywords:

kurikulum 2013,

pelatihan, pembelajaran inovatif berbasis karakter karakter, 2. kemampuan menggunakan ragam strategi inovatif yang sesuai dengan konteks dan kondisi pembelajaran di sekolah masing-masing, 3. kemampuan mengembangkan RPP menggunakan pengalaman belajar yang sesuai dengan kaidah pembelajaran inovatif dan pendidikan karakter berdasarkan kurikulum 2013. Bentuk aktivitas (modes of activitiy) dirancang menggunakan strategi pelatihan (training) dalam bentuk 'pelatihan, mengingat para calon peserta sedikit tidaknya telah memiliki pengetahuan dan pengalaman di bidang pembelajaran bahasa Inggris dan strategi pembelajaran bahasa Inggris untuk siswa SMP, SMA dan SMK. Tahapan-tahapan aktivitas secara umum menggunakan strategi pembelajaran Information Processing Theory, yaitu: penyemaian informasi (encoding), pengintegrasian informasi menjadi suatu pemahaman (decoding), perekaman informasi (storing), pelatihan informasi (rehearsal), dan pembelajaran informasi (learning). Pengabdian pada Masyarakat yang dilakukan di Ruteng, Flores, tergolong sukses karena tujuan yang direncanaan bisa tercapai. Dari hasil evaluasi, pencapaian ini dikonfirmasi dari wawancara dengan guru. Pada dasarnya para guru merasa telah belajar sesuatu yang penting dari kegiatan pelatihan dan berharap bahwa kegiatan semacam ini bisa dilakuan lagi di masa yang akan datang.
\end{abstract}

\section{Pendahuluan}

Sejak dibelakukannya kurikulum berbasis kompetensi sejak 2004, pembelajaran sudah mengalami perubahan paradigma dari pembelajaran berposat kepada guru menjadi berpusat pada siswa. Kurikulum Tingkat Satuan Pendidikan yang kemudian diberlakukan pada tahun 2006 lebih menekankan perlunya pembelajaran yang inovatif, inspiratif, menyenangkan, memotivasi dan menantang. Sesungguhnya sejak tahu 2006 itulah istilah pembelajaran mulai gencar dipakai didunia pendidikan. Berbagai pelatihan tentang pembelajaran inovatif mulai Kurikulum 2013 yang diperkenalkan sebagai pengganti KTSP memiliki standar proses dan pendekatan pembelajaran yang baru, namun konsep pembelajaran inovatif tidak berubah. Bahkan kebutuhan untuk mampu merancang pembelajaran inovatif semakin dibutuhkan, terutama yang sekaligus memasukkan pendidikan karakter sebagaimana yang dirumuskan dalam salah satu kompetetensi inti Kurikulum 2013.

Di Provinsi Bali, pelatihan, seminar, lokakarna, professional development maupun bentuk kegiatan lain yang mengambil topik pembelajaran inovatif dan juga pendidikan karakter sudah sangat sering dilakukan. Bisa dikatakan bahwa hamper semua guru di Bali sudah tersentuh kegiatan sosialisasi maupun pelatihan tentang pembelajaran inovatif. 
Namun demikian, sekolah-sekolah di berbagai wilayah di NTT belum banyak tersentuh oleh kegiatan pelatihan maupun professional development tentang pembelajaran inovatif dan pendidikan karakter. Kebutuhan untuk mengadakan progam-program pelatihan bagi guru-guru, khususnya guru Bahasa Inggris di Nusa Tenggara Timur, khususnya di Kabupaten Manggarai Barat sangat diperlukan karena dua alasan utama. Pertama, memang karena alasana kurangnya kegiatan pelatihan dan professional development yang menyasar guru-guru Bahasa Inggris di Manggarai. Kedua, Kabupaten Manggarai Barat merupan kabupaten yang memiliki potensi wisata yang sangat mengagumkan termasuk adanya Pulau Komodo yang terkenal di seluruh dunia. Ada potensi besar bagi kabupaten ini untuk mengembangkan ekonomi kreatifnya di bidang pariwisata. Dengan demikian kebutuhan untuk bisa berbahasa Inggris menjadi semakin tinggi. Ini disadari oleh lembaga pendidikan tinggi yang ada di Manggarai.

Adapun masalah yang mendasari ide pelaksanaan kegiatan Pengabdian pada Masyarakat ini adalah 1) Sosialisasi, pelatihan maupun kegiatan-kgiatan Professional Development tentangn implementasi Kurikulum 2013 belum banyak dilakukan di NTT, khususnya Kabupaten Manggarai Barat. 2) Pembelajaran dengan kurikulum baru memerlukan strategi inovatif yang bisa memadukan pembelajaran dengan target pengembangan kemampuan kognitif sekaligus karakter sehingga pembelajaran bisa berlangsung secara natural dan menyenangkan. 3) Perlu adanya pelatihan bagi guruguru bahasa Inggris se-Kabupaten Manggarai Barat agar mampu merancang pembelajaran bahasa Inggris yang berbasis sains yang kreatif

Kegiatan Pengabdian pada masyarakat ini memiliki tujuan agar guru-guru bahasa Inggris SMP, SMA dan SMK se Kabupaten Manggarai Barat agar memiliki: 1. pengetahuan konsep pembelajaran inovatif sesuai dengan Kurikulum 2013 yang menyasar pencapaian kognitif dan pendidikan karakter, 2 . kemampuan menggunakan ragam strategi inovatif yang sesuai dengan konteks dan kondisi pembelajaran di sekolah masing-masing, 3. kemampuan mengembangkan RPP menggunakan pengalaman belajar yang sesuai dengan kaidah pembelajaran inovatif dan pendidikan karakter berdasarkan kurikulum 2013.

Kegiatan Pengabdian pada Masyarakat ini diharapkan akan memberi manfaat yangsignifikan terhadap pihak-pihak sebagai berikut: 1.Bagi Guru Bahasa Inggris, kegiatan P2M ini diharapkan mampu menjembatani harapan pemerintah dalam Kurikulum 2013 tentang pembelajaran inovatif dan pendidikan karakter dengan kondisi persekolahan riil yang terjadi di Kabupaten Manggarai Barat. 2. Bagi SMP dan SMA se-Kabupaten Manggarai Barat, kegiatan P2M ini akan secara langsung memiliki kontribusi positif terhadap kualitas pembelajaran bahasa Inggris yang berkualitas yang akan memberi motivasi dan minatpeserta didik untuk belajar bahasa Inggris. 3. Bagi UNDIKSHA, sebagai sebuah LPTK, kegiatan P2M ini akan menjadi salah satu wujud kepedulian lembaga pendidikan ini untuk berperan aktif dalam meningkatkan kualitas SDM (guru) di wilayah Indonesia umumnya dan di Kabupaten Manggarai Barat khususnya.

\section{Metode}

Adapun tahapan dari identifiasi masalah sampai dengan dilaksanakannya kegiatan P2M ini mengikuti alur seperti yang digambarkan pada diagram di bawah ini:

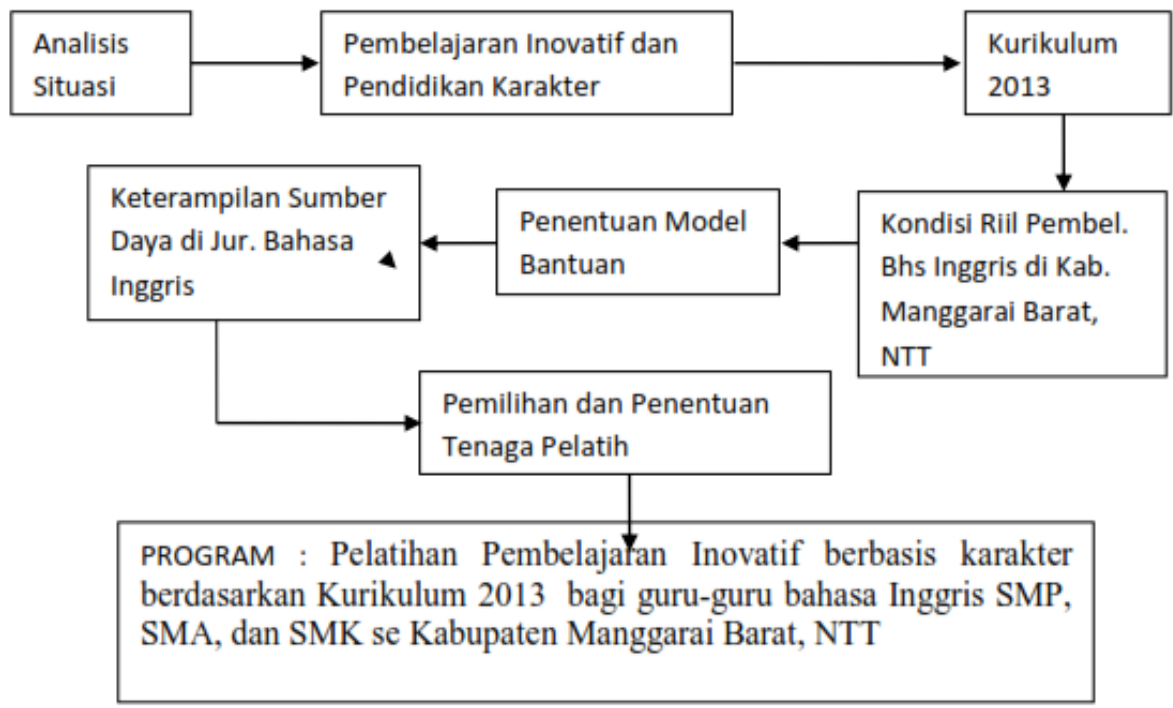


Peserta sasaran yang akan diundang untuk mengikuti kegiatan P2M ini adalah 50 orang guru-guru Bahasa Inggris SMP, SMA dan SMK se kabupaten Manggarai Barat P2M ini akan melibatkan khalayak sasaran untuk mendukung pelaksanaan pengabdian ini, antara lain: (1) Kepala Dinas Pendidikan Kabupaten Manggari Barat, NTT. (2) Rektor Universitas Pendidikan Ganesha, (3) Para guru Bahasa Inggris SMP, SMA, dan SMK se Kabupaten Manggarai Barat, NTT dan, (4) Para kepala sekolah terkait. Bentuk aktivitas (modes of activitiy) dirancang menggunakan strategi pelatihan (training) dalam bentuk 'pelatihan, mengingat para calon peserta sedikit tidaknya telah memiliki pengetahuan dan pengalaman di bidang pembelajaran bahasa Inggris dan strategi pembelajaran bahasa Inggris untuk siswa SMP, SMA dan SMK. Tahapan-tahapan aktivitas secara umum menggunakan strategi pembelajaran Information Processing Theory, yaitu: penyemaian informasi (encoding), pengintegrasian informasi menjadi suatu pemahaman (decoding), perekaman informasi (storing), pelatihan informasi (rehearsal), dan pembelajaran informasi (learning). Oleh karena itu, pelatihan ini akan dimulai dengan pemberian informasi secara kelompok, pemberian daftar strategi pembelajaran inovatif dan contoh implementasi pembelajaran inovatif berbasis karakter dalam pembelajaran bahasa Inggris, pemberian tugas individual dan kelompok, kegiatan praktek dalam kelompok kecil. Adapun langkah terakhir adalah proses evaluasi dan refleksi terhadap efektifitas program. Selanjutnya, seusai kegiatan pelatihan, diharapkan semua pengetahuan dan keterampilan yang diperoleh peserta bisa dipergunakan untuk meningkatkan kualitas pembelajaran bahasa Inggris di sekolah masing-masing.

Dalam kaitannya dengan workshop "Pelatihan Pembelajaran Inovatif Berbasis Karakter Berdasarkan Kurikulum 2013 Bagi Guru-Guru Bahasa Inggris SMP, SMA, dan SMK Se Kabupaten Manggarai Barat", kegiatan monitoring dan evaluasi dilaksanakan melalui pengamatan langsung terhadap penampilan (performance) para peserta dalam kegiatan kelompok maupun simulasi dan kuesioner kepuasan peserta.

\section{Hasil dan Pembahasan}

Kegiatan Pengabdian pada Masyarakat ini dilaksanakan pada tanggal 10-11 Juni 2016. Jadwal ditetapkan setelah secara intens dilakukan komunikasi dengan institusi mitra guru-guru bahasa Inggris di, yaitu: STKIP Santa Paulus Ruteng. Pelaksanaan kegiatan pengabdian pada Masyarakat ini memang merupakan kebutuhan riil di lapangan dimana kabupaten Manggarai Barat memiliki semangat dan motivasi untuk bisa menyerenggarakan proses pembelajaran bahasa Inggris yang berkualitas karena kabupaten Manggarai saat ini sedang berkembang menjadi daerah tujuan wisata internasional. Kebutuhan untuk bisa berkomunikasi dalam bahasa Inggris semakin dirasakan oleh generasi muda khususnya lulusan sekolah (SMP, SMA, dan SMK). Sebagai mitra dalam kegiatan ini, STKIP Santa Pulus membantu mengundang para peserta serta berkoordinasi dengan Dinas pendidikan setempat, serta menyediakan tempat untuk pelatihan. Sementara itu, nara sumber berkordinasi sera menyiapkan materi, baik dalam sesi auditori maupun dalam lokakarya.

Kegiatan pembukaan dihadiri oleh para undangan dan peserta. Jumlah undangan ada 14 orang, 10 diantaranya adalah dosen Pendidikan Bahasa Inggris. Selain itu, undangan adalah dari Dinas Pendidikan dan dari Menejemen kampus. Pada sesi pemaparan materi, peserta sangat ktif dan banyak bertanya. Ini menunjukkan bahwa kegiatan memang bermakna/bermanfaat bagi peserta. Ada banyak "curhatan" dari guru tentang kondisi kelasnya. Selain itu guru juga menjelaskan tentang kendala-kendala untk implementasi metode pembelajaan inovatif. Misalnya, kemampuan siswa yang sangat rendah dalam berbahasa Inggris sehingga guru merasa pesimis jika mengimplementasikan metode inovatif yang mengharuskan siswa berpartisipasi aktif. Tetapi dengan penjelasan dan contoh-contoh sederhana, maka masalah cenderung bisa diatasi. Pada kegiatan mapping topik, para guru dikelompokkan berdasarkan kelas. Mereka harus menganalisis silabus untuk selanjutnya ditentukan strategi yang kira-kira tepat atau sesuai dengan indikator dan ciri-ciri metode pembelajaran inovatif.

Pada hari kedua, jumlah peserta bertambah, karena ada mahasiswa Pendidikan Bahasa Inggris yang akan melaksanakan PPL ikut bergabung. Mereka ingin belajar tentang merencanakan pembelajaran yang menggunakan metode inovatif. Para guru dikelompokkan dengan mahasiswa dan mereka mengembangkan RPP. Kegiatan pertama di hari kedua adalah pemodelan implementasi metode inovatif dengan lagu dan permaianan. Para peserta disuguhi sebuah video pembelajaran dan setelah itu dilakukan diskusi tentang langkah-langkah yang diterapkan dan nilai karakter yang mungkin bisa dikembangkan. Selanjutnya mereka diberi contoh RPP dan diskusi kembali dilakukan tentang RPP tersebut. Setelah itu barulah mereka dikelompokkan dan disuruh memutuskan KD dan indikator yang ingin dicapai dan dari sini RPP mereka kembangkan secara bersama-sama. Saat kegiatan diskusi kelompok, narasumber berkeliling untuk mengamati serta melayani pertanyaan dari peserta. Mereka 
dimotivasi untuk menggunakan pemikiran inovatif di setiap segmen pembelajaran, yaitu: mengobservasi, menanya, mengumpulkan informasi, mengasosiasi dan mengomunikasikan. Waktu yang disediakan untuk pengembangan RPP adalah 2 jam. Waktu tersebut digunakan dengan sangat baik oleh setiap kelompok dimana di akhir waktu yang dialokasikan, semua kelompok sudah menyelesaikan rancangannya. Selanjutnya ketua kelompok mempresentasikan RPP tersebut dan peserta lain dan fasilitator memberikan komentar dan masukan untuk menyempurnakan perencanaan pembelajaran tersebut. Setelah makan siang, dilakukan simulasi yang menggambarkan hasil peltihan yang diikuti oleh peserta. Kegiatan ini sangat menarik karena peserta sangat bersemangat untuk menunjukkan hasil pemikiran kreatif mereka. Semua peserta bisa belajar dari simulasi kelompok lain. Karena bersemangatnya, waktu terasa berjalan cepat sehingga tidak semua kelompok mendapat giliran. Tepat pukul 3 sore, kegiatan pelatihan dan lokakarya diakhiri. Pengisisan angket untuk evaluasi terpaksa ditiadakan, digantikan engan wawancara dengan beberapa peserta. Berdasarkan pengamatan dan wawancara secara random bisa disimpulkan bahwa acara pelatihan dan lokakarya tergolong sukses.

\section{Simpulan dan Saran}

Pengabdian pada Masyarakat yang dilakukan di Ruteng, Flores, tergolong sukses karena tujuan yang direncanaan bisa tercapai. Tujuan yang dimaksud antara lain untuk (i) membangun pengetahuan konsep pembelajaran inovatif sesuai dengan Kurikulum 2013 yang menyasar pencapaian kognitif dan pendidikan karakter, (ii) untuk meningkatkan kemampuan menggunakan ragam strategi inovatif yang sesuai dengan konteks dan kondisi pembelajaran di sekolah masing-masing, dan (iii) untuk menyembangkan kemampuan mengembangkan RPP menggunakan pengalaman belajar yang sesuai dengan kaidah pembelajaran inovatif dan pendidikan karakter berdasarkan kurikulum 2013. Dari hasil evaluasi, pencapaian ini dikonfirmasi dari wawancara dengan guru. Pada dasarnya para guru merasa telah belajar sesuatu yang penting dari kegiatan pelatihan dan berharap bahwa kegiatan semacam ini bisa dilakuan lagi di masa yang akan datang.

Kegiatan Pengabdian Pada Masyarakat yang dilaksanakan di luar daerah ternyata bisa bermanfaat bagi para guru di daerah tersebut. Untuk itu perlu adanya kerjasama yang baik yang didasari oleh MOU antara LPTK dengan Dinas-dinas Pendidikan di daerah sehingga kegiatan semacam ini bisa terjadwal secara berkelanjutan.

\section{Daftar Pustaka}

Artini, L.P. (2010). Feasible Bilingual Education Model in International Standard School in Indonesian Context: Theoretical Perspectives. A paper presented at Multidisciplinary International Conference on Education and Culture, Flores, 16 - 15 July 2010.

Artini, L.P. (2009). Profil Penggunaan Bahasa Inggris Dalam Pembelajaran Matematika dan Sains di Kelas Bilingual di Sekolah Negeri Rintisan Berstandar Internasional di Bali. Laporan Penelitian: IMHERE Project.

Artini, L.P. (2006). T Learning English in Bali: Investigating Beliefs and Language Learning Strategies . Unpublished PhD Thesis. Newcastle University.

Anderson \& Krathwohl. (2004). Taxonomy of Teaching, Learning, and Assessing a Revision of Bloom's Taxonomy. N.Y: Allyn and Bacon.

Cummins, J. (2003). "Bilingual Education: Basic Principles" in Dewaele J.M, Alex Housen \& Li Wei (eds). Bilingualism: Beyond Basic Principles. Clevedon: Multilingual Matters Ltd.

Dardjowidjojo, S. (2000). English teaching in Indonesia. English Australia Journal. 18 (1). 22-30.

Depdiknas. (2008). Panduan Pelaksanaan Pembinaan Rintisan SMP-SBI. Jakarta: Depdiknas.

---------- (2007). Sistem Penyelenggaraan Sekolah Bertaraf Internasional (SBI) untuk Pendidikan Dasar dan Menengah. Jakarta: Direktorat Pembinaan Sekolah Menengah Atas - (2007). Panduan penyelenggaraan Rintisan SMA Bertaraf Internasional. Jakarta: Depdiknas. - (2006). Menuju Pembangunan Pendidikan Nasional Jangka Panjang 2025. Jakarta: Direktorat Pembinaan Sekolah Menengah Atas

Dewaele, J.M., Alex Housen \& Li Wei (2003) (eds) Bilingualism: Beyond Basic Principles. Sydney: Multilingual Matters Ltd.

Elliott, S.N. et al. (2000). Educational Psychology: Effective Teaching, Effective Learning. Boston: Mc.Graw Hill.

Faltis, C.J. and S.J Hudelson. (1998). Bilingual Education in Elementary and Secondary 
School Communities. Toward Understanding and Caring. Boston: Allyn and Bacon Hudson, P. (2009). Learning to Teach Science Using English as a Medium of Instruction. Eurasia Journal of Mathematics, Science \& Technology Education, Vol 5 No.2, pp. $165-170$

National Association for Bilingual Education (2004). What is a Bilingual Education? Internet: http//www.nabe.org (upload tgl 20 Maret 2009).

Sutman, F.X. (1993). Teaching Science Effectively to Limited English Proficient Students. In ERIC/CUE Digest, No. 87 (download 31 July 2010). 